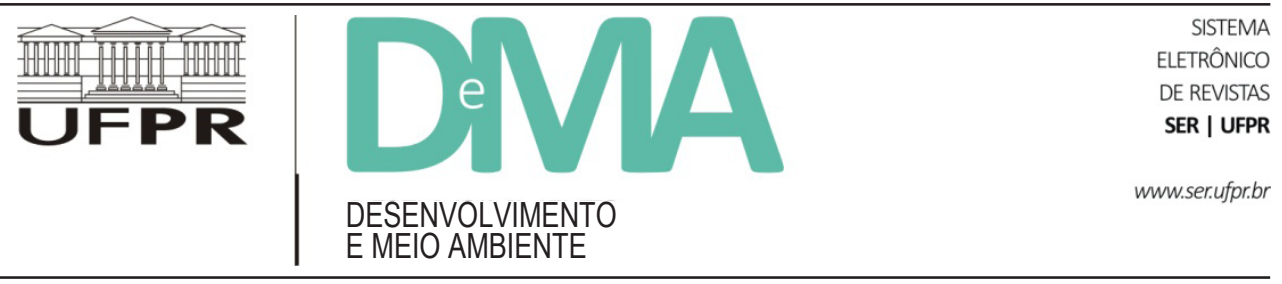

\title{
A representação social do meio ambiente na leitura comunitária do Plano Diretor de Palmas (TO)
}

\section{A Social Representation of the Environment in the Community Reading of Palmas (TO) Developing Plan}

\author{
Daniela Barbosa de OLIVEIRA ${ }^{1 *}$, Antonelli Santos SILVA $^{2}$, Charles Albert GUERRA ${ }^{3}$, Karine Beraldo \\ Magalhães OLIVEIRA ${ }^{4}$, Lucas Barbosa e SOUZA ${ }^{5}$, Márcio Galdino dos SANTOS ${ }^{5}$ \\ ${ }^{1}$ Grupo de Pesquisa Observatório de Pesquisas Aplicadas ao Jornalismo e ao Ensino (OPAJE), Universidade Federal do Tocantins (UFT), \\ Palmas, TO, Brasil. \\ ${ }^{2}$ Instituto Federal de Educação, Ciência e Tecnologia do Tocantins (IFTO), Palmas, TO, Brasil. \\ ${ }^{3}$ Faculdade de Palmas (FAPAL), Palmas, TO, Brasil. \\ ${ }^{4}$ Instituto Federal de Educação, Ciência e Tecnologia do Tocantins (IFTO), Paraíso do Tocantins, TO, Brasil. \\ ${ }^{5}$ Programas de Pós-Graduação em Ciências do Ambiente, Universidade Federal do Tocantins (UFT), Palmas, TO, Brasil. \\ *E-mail de contato: kallaw2@gmail.com
}

Artigo recebido em 6 de junho de 2015, versão final aceita em 25 de outubro de 2015.

RESUMO: O plano diretor é o instrumento que norteia a gestão e a ocupação de um município, sendo que seu processo de elaboração deve contar com ampla participação da sociedade por meio de audiências públicas. Em 2005, o município de Palmas, no Tocantins, deu início à construção de seu primeiro Plano Diretor Participativo, que culminou na Lei Complementar no 155/2007. O presente trabalho buscou traçar o histórico de construção desse plano diretor por meio de entrevistas com participantes da equipe gestora do processo, análise de documentos e da legislação final com o objetivo de compreender como o meio ambiente foi representado nesse processo. A teoria da representação social serviu de base para este estudo. Seguindo o método da Análise de Conteúdo, as questões ambientais foram associadas a categorias de representação social de meio ambiente. Verificou-se que nas audiências públicas a comunidade representou o meio ambiente tendo o homem como elemento central, na maioria dos casos. Constatou-se que o conteúdo levantado pela comunidade durante as audiências de construção do Plano foi contemplado na lei final, contudo, de forma diluída e com expressões generalizantes que podem desvirtuar a aplicação desta lei no atendimento aos anseios da comunidade. Esta característica demonstra a necessidade de maior reflexão sobre a participação popular e sua reformulação para revisão do próximo Plano Diretor Participativo de Palmas.

Palavras-chave: meio ambiente; Palmas; Plano Diretor Participativo; representação social. 
ABSTRACT: The developing plan is the instrument that guides the management and occupation of a municipality, and its development process must rely on broad participation of society via public hearings. In 2005 , the city of Palmas, Tocantins, began the construction of its first participative developing plan, culminating in Complementary Law $n^{0} .155 / 2007$. The present study sought to trace the history of the construction of this developing plan through interviews with team members that managed the process, review of documents and the final legislation. In order to understand how the environment was represented in the documents, we used the theory of social representation, and environmental issues were associated with categories of social representation of the environment. We verified that the community hearings represented the environment with man as the central element in most cases. We found that the content raised by the community during the hearings for the plan's construction was contemplated in the final law, but in a diluted form and generalizing expressions that can detract from the application of this law in serving the aspirations of the community. This characteristic demonstrates the need for further reflection on popular participation and its reformulation for review aiming the next Palmas Participative Developing Plan.

Keywords: environment; Palmas; participative developing plan; social representation.

\section{Introdução}

O município de Palmas, capital do Estado do Tocantins, foi a última cidade brasileira planejada construída no século XX. Embora seu desenho e seu plano diretor inicial tenham sido pensados tendo como base estudos de urbanistas, na sua implantação o que se observou, segundo Lira (2011), foi o crescimento desordenado, o que denota certa tensão entre o planejamento e a gestão da cidade.

Com as mudanças trazidas pelas diretrizes gerais do Estatuto da Cidade, no que tange à garantia do direito à cidade sustentável e à gestão democrática por meio da participação popular e das entidades, tiveram início, em 2005, discussões que culminaram na elaboração do Plano Diretor Participativo de Palmas, aprovado por lei municipal no ano de 2007.

Esse Plano, por ser participativo, teve como premissa básica o fortalecimento institucional do processo de planejamento e gestão do município, o envolvimento e a capacitação dos servidores efetivos e das representações comunitárias e a ampla participação da sociedade, por meio de plenárias, consultas e audiências públicas, conforme informado em seu próprio texto (Palmas, 2007).

Após a leitura técnica, seu processo de construção contou com a realização de diversas consultas públicas, em vários setores do município (urbanos e rurais), abertas a várias instituições, entidades classistas e a segmentos da população. O propósito desse processo foi fazer a leitura comunitária, ou seja, identificar, representar e entender a situação do município em toda a sua extensão, seus problemas, conflitos e potencialidades, pressupondo olhares diversos sobre uma mesma realidade (Queiroz et al., 2006).

O Plano Diretor Participativo de Palmas é resultado de uma construção coletiva, que passou por diferentes etapas de redação. Assim, o conteúdo levantado ao longo da leitura técnica e da leitura comunitária, esta última por meio das audiências públicas, pode ter sofrido alterações significativas até a chegada do Projeto de Lei à Câmara Municipal para discussão. Ressalta-se que, para sua aprovação em Lei Municipal, o Plano Diretor pode, ainda, ter recebido diferentes redações resultantes das discussões por parte dos vereadores.

Neste sentido, este trabalho tem como objetivo analisar a representação social de meio ambiente presente nos relatórios das audiências públicas e na Lei Complementar $n^{\circ}$ 155/2007, atual Plano Diretor de Palmas - TO, bem como verificar a metodologia participativa empregada na construção deste plano.

Para compreender melhor como se deu a participação popular, foram realizadas entrevistas semiestruturadas com alguns participantes da equipe gestora municipal do Plano Diretor. Ainda, usou-se como base desse estudo relatórios e textos resultantes do processo de elaboração do Plano Diretor Participativo de Palmas, tais como o "Relatório de Consulta Pública do Plano Diretor", o "Relatório da Leitura Comunitária" e a "Lei Complementar $\mathrm{n}^{\circ}$ 155/2007". Ao se fazer o estudo dos 
relatórios que expunham a participação dos presentes nas audiências públicas, foi observado como as pessoas representavam o meio ambiente pelo uso das expressões contidas no eixo temático denominado "meio ambiente".

Seguindo a técnica da Análise de Conteúdo que, segundo Vergara (2006, p. 15), permite fazer o "tratamento de dados que visa identificar o que está sendo dito a respeito de determinado tema", estas expressões foram relacionadas à representação social de meio ambiente usando as categorias propostas por Sato (2002), Neves (2003) e Reigota (2004), que permitiram identificar a representação social de meio ambiente nas etapas mencionadas de elaboração do Plano Diretor Participativo de Palmas.

\section{Planos Diretores participativos}

O plano diretor constitui o instrumento básico de planejamento dos municípios, pois a partir dele se originam as diretrizes e as normativas para o adequado uso e ocupação do solo urbano, o que deve assegurar o atendimento das necessidades dos cidadãos quanto à qualidade de vida, justiça social e desenvolvimento das atividades econômicas (Brasil, 2001).

A Constituição Federal de 1988 foi a primeira, no âmbito da legislação brasileira, a mencionar o plano diretor, vinculando-o ao artigo 182, inserido em um capítulo específico sobre a política urbana. Contudo, este capítulo necessitava de uma regulação específica, o que só veio a ocorrer treze anos depois, sob a forma da lei denominada Estatuto da Cidade (Oliveira \& Sahr, 2012).

O Estatuto da Cidade, Lei Federal $n^{\circ} 10.257 / 2001$, fixou as diretrizes gerais da política urbana e estabeleceu que o plano diretor deve apresentar caráter participativo, de forma a operacionalizar a gestão democrática da cidade. Seguindo essa lógica, a construção desse documento se dá de forma a assegurar a participação popular efetiva, uma vez que cabe aos moradores da cidade apontar os problemas e propostas para a melhoria das suas condições de vida (Dornelas et al., 2001).

Logo, os planos diretores, chamados participativos e implantados no início do século XXI, devem ser instrumentos concebidos originalmente com vistas à gestão democrática, pois neles os interesses de diversos agentes sociais devem confrontar-se, numa tentativa de compatibilizar as ações e investimentos públicos com as demandas e interesses das classes sociais presentes na sociedade (Sousa, 2010).

Segundo o Ministério das Cidades (Brasil, 2005), o plano diretor participativo deve passar por diferentes fases de elaboração, que vão desde a composição da equipe responsável por sua gestão (com representantes do poder público e da sociedade civil) e sua capacitação para as atividades às etapas de construção em si.

As etapas construtivas do plano envolvem a elaboração de leituras técnica e comunitária que permitem identificar, mapear e entender a situação do município e formular e pactuar propostas com perspectiva estratégica, assim como planejar instrumentos de viabilidades dos objetivos, estratégias municipais e o sistema de gestão do município. Essas etapas culminam com a construção do Projeto de Lei do plano diretor municipal, o qual é discutido na Câmara Municipal e transformado em lei municipal.

A fim de garantir a efetiva participação social para a elaboração das leituras técnica e comunitária, a construção do plano diretor participativo deve ser acompanhada de audiências públicas e debates com a participação da população e de associações representativas dos vários segmentos da sociedade, bem como da publicidade e do acesso de qualquer interessado aos documentos e informações produzidos.

Contudo, apesar de todas as etapas de elaboração do plano diretor municipal pautarem pela participação popular, Saleme e Silva (2006) lembram que mesmo com a convocação da população e associações representativas para participação no plano diretor e nas audiências públicas ter sido adotada em diversos municípios, a mesma não tem alcançado um resultado satisfatório em termos participativos. Na prática, parte das diretrizes elaboradas nos planos diretores não conta com uma efetiva participação popular. Os autores argumentam ainda sobre a necessidade de se exigir das autoridades competentes a implantação das políticas e instrumentos consignados no plano diretor pela população, indicando a importância do controle por parte dos poderes legislativo e judiciário, além do próprio controle popular.

Conforme Stephan e Rocha (2009), um dos motivos da baixa participação social na elaboração dos planos diretores participativos é a falta de um histórico de participação da população nos processos decisórios 
em relação ao destino da cidade. Embora, no Brasil, a participação popular não esteja idealmente incorporada (Souza, 2010), desde a Constituição de 1988, paulatinamente a democratização dos processos decisórios vem conscientizando os cidadãos sobre o seu papel no planejamento dos espaços urbanos. É digno de nota que a conquista desse espaço é resultado de um anseio coletivo, por meio de movimentos populares (Ribeiro \& Cardoso, 2003).

Por um lado, mesmo a ampla participação popular na formulação do plano diretor não elimina erros e não é garantia de acerto (pois uma coletividade pode, livre e soberanamente, tomar uma decisão injusta e equivocada); por outro, uma ampla participação pode contribuir para minimizar certas fontes de distorção, monitorar ou controlar os governantes e diminuir os erros de avaliação, uma vez que, ao participar de uma decisão, o cidadão se sente mais responsável pelo seu resultado, de modo geral (Souza, 2010).

Apesar de todas essas considerações, o plano diretor é parte integrante e indissociável do processo de planejamento municipal, logo, precisa incorporar os problemas da cidade e suas soluções, de forma que atenda aos anseios da população (Antunes, 2006).

A oportunidade dada à população de participar do processo de elaboração do plano diretor talvez seja o primeiro passo para a tomada de consciência política pela população para a gestão cooperativa entre governo e sociedade. Essa abertura desempenha, deste modo, uma função pedagógica, que vem mostrar à sociedade que é possível se fazer uma cidade mais justa e acessível para todos (Stephan \& Rocha, 2009).

Contudo, este processo deve ser acompanhado por mecanismos que ampliem e incentivem a participação da sociedade nos processos decisórios, garantindo a autonomia coletiva, por meio de discussões públicas e livres que forneçam todas as informações necessárias para um autêntico planejamento participativo da produção do espaço.

\section{A representação social de meio ambiente}

Um importante teórico que contribuiu para o desenvolvimento do conceito de representação social foi Durkheim, em Representações individuais e representações coletivas, no qual diferencia duas formas de representação: individual e coletiva. A primeira representando a consciência de cada um, subjetiva, flutuante e, por isso, perigosa à ordem social; e a segunda, representando a sociedade, por seu caráter impessoal e permanente, permitindo assim a harmonia da sociedade (Moscovici, 2003).

No Brasil, a publicação dos estudos sobre o conceito de representação social de Serge Moscovici foi feita em 1978, sob o título A representação social da psicanálise, referindo-se ao posicionamento e à localização da consciência subjetiva em contextos. As representações de um objeto social passam por um processo de formação entendido como um encadeamento de fenômenos interativos, fruto dos processos sociais no cotidiano do mundo contemporâneo. Nesse aspecto, o conceito de representação social trabalha com uma gama de elementos que envolvem teorias científicas, ideologias e experiências vivenciadas no cotidiano, englobando, dessa forma, questões ligadas à Psicologia, à Comunicação e à Sociologia (Moscovici, 1978).

Moscovici explica que existem dois universos de pensamento nas sociedades contemporâneas "pensantes": o reificado (da ciência) e o consensual (do senso comum). O reificado consiste na fixação e na preservação do rigor lógico e metodológico do conhecimento, bem como sua estratificação hierárquica. Já o universo consensual consiste no mundo em vivemos, no seu cotidiano e nas conversas informais. As representações sociais tratam do universo consensual, são criadas pelos processos de ancoragem e objetivação. A objetivação é o mecanismo que procura "transformar algo abstrato em algo quase concreto, transferir o que está na mente em algo que exista no mundo físico", objetivando-o. A ancoragem mantém a memória em movimento, sempre absorvendo e descartando objetos, pessoas e acontecimentos, que ela classifica com nomes e de acordo com tipos (Moscovici, 2003, p. 60-61).

As representações sociais devem ser estudadas articulando elementos afetivos, mentais e sociais e integrando, ao lado da cognição, da linguagem e da comunicação, a consideração das relações sociais que afetam as representações e a realidade material, social e ideal sobre a qual elas intervêm (Jodelet, 1989). 
Os trabalhos de Sato (2002), Neves (2003) e Reigota (2004) são importantes para compreender esses elementos da representação social, tomando-se como referência o meio ambiente. Sato (2005) adaptou de Sauvé (2005) as categorias complementares de representação de meio ambiente, as quais são classificadas em sete categorias: 1) Como natureza: elementos da natureza (fauna e flora) além de paisagens (pôr do sol, etc.); 2) Como recurso: representações sobre o potencial econômico para o desenvolvimento humano; 3) Como problema: associadas às queimadas, desmatamento, poluição de recursos hídricos, etc.; 4) Como sistema: mostram as relações entre os ecossistemas, na tentativa de auxiliar na manutenção da vida no planeta Terra; 5) Como meio de vida: caracterizadas pelas representações da casa onde se mora e de seu entorno; 6) Como biosfera: o planeta Terra; 7) Como projeto de vida: mostram a relação de interdependência da sociedade com a natureza.

Neves (2003), por sua vez, destaca a existência de duas concepções básicas sobre meio ambiente, a naturalista e a sistêmica. A naturalista, que percebe o meio ambiente somente como natureza, enfatiza a defesa e a proteção do meio ambiente ou descreve o homem como espoliador da natureza; e a sistêmica, que incorpora a dimensão sociocultural no seu conceito de meio ambiente ou considera vários setores para a resolução de questões ambientais ou propõe práticas interdisciplinares (Neves, 2003).

Para Reigota (2004), o conceito de meio ambiente deve ser considerado sob um viés socioambiental, já que leva em conta não só os aspectos naturais e físicos, como também as relações sociais, culturais, históricas e tecnológicas entre os elementos envolvidos. Contudo, não existe um consenso sobre meio ambiente na comunidade científica em geral, sendo que, para este autor, a noção de meio ambiente é uma representação social. De acordo com Reigota (2004), a representação do meio ambiente pode ser classificada em três categorias: 1) Naturalista, por meio da qual o meio ambiente é compreendido como ecossistema e todas as suas categorias de complexidade, tendo como prioridade a sua conservação; 2) Antropocêntrica, na qual o meio ambiente é tido exclusivamente como meio de exploração de recursos; 3) Globalizante, em que há uma relação de interdependência entre homem e natureza, incluindo os aspectos político, social, econômico e cultural.
Por fim, é importante compreender que a teoria das representações sociais consiste na produção dos saberes sociais, centrando-se na análise da construção e transformação do conhecimento social. As representações são, então, uma maneira de interpretar e comunicar, mas também de produzir e elaborar conhecimento.

\section{O planejamento de Palmas e o processo de ocupação}

O município de Palmas, capital do Tocantins, localizado em sua região central (Figura 1), foi fundado no ano de 1989, logo após a criação do Estado pela Constituição de 1988. O primeiro Plano Diretor dessa cidade (Lei no 468 de 06 de janeiro de 1994) foi elaborado pela equipe que projetou a cidade: o Grupo Quatro (escritório de arquitetura de Goiânia). Segundo Velasques (2009), este plano estruturou o partido urbanístico de Palmas sobre a proposta de um sistema viário hierarquizado e orientado pelos pontos cardeais, junto a elementos paisagísticos relevantes - a serra do Lajeado, a leste, e o rio Tocantins, a oeste, ambos em paralelo ao sítio relativamente plano destinado à cidade. Por sua vez, foram setorizadas quadras organizadas segundo os usos, além de áreas de preservação ambiental junto aos córregos que descem da mencionada serra em direção ao rio Tocantins, acrescentando-se ainda a determinação de algumas diretrizes de planejamento da ocupação do espaço urbano futuro, voltadas para o controle da expansão e otimização dos custos relativos à implantação da infraestrutura.

Velasques (2009) explica ainda que o sistema viário foi estabelecido por dois eixos estruturantes: um no sentido norte-sul, chamado Avenida Teotônio Segurado, e outro, no sentido Leste-Oeste, chamado Avenida Juscelino Kubitschek, das quais surgem paralelamente as avenidas norte-sul, "N-S", e as Leste-Oeste, "L-O", sendo que em seus cruzamentos inscrevem-se rotatórias dimensionadas segundo o tráfego e a densidade de cada área. A nomenclatura das quadras referencia-se pelos eixos principais e pelos pontos cardeais. Logo, Palmas foi subdividida em quatro porções: Nordeste - quadras chamadas ARNE's; Noroeste - quadras chamadas ARNO's; Sudeste - quadras chamadas ARSE's; 


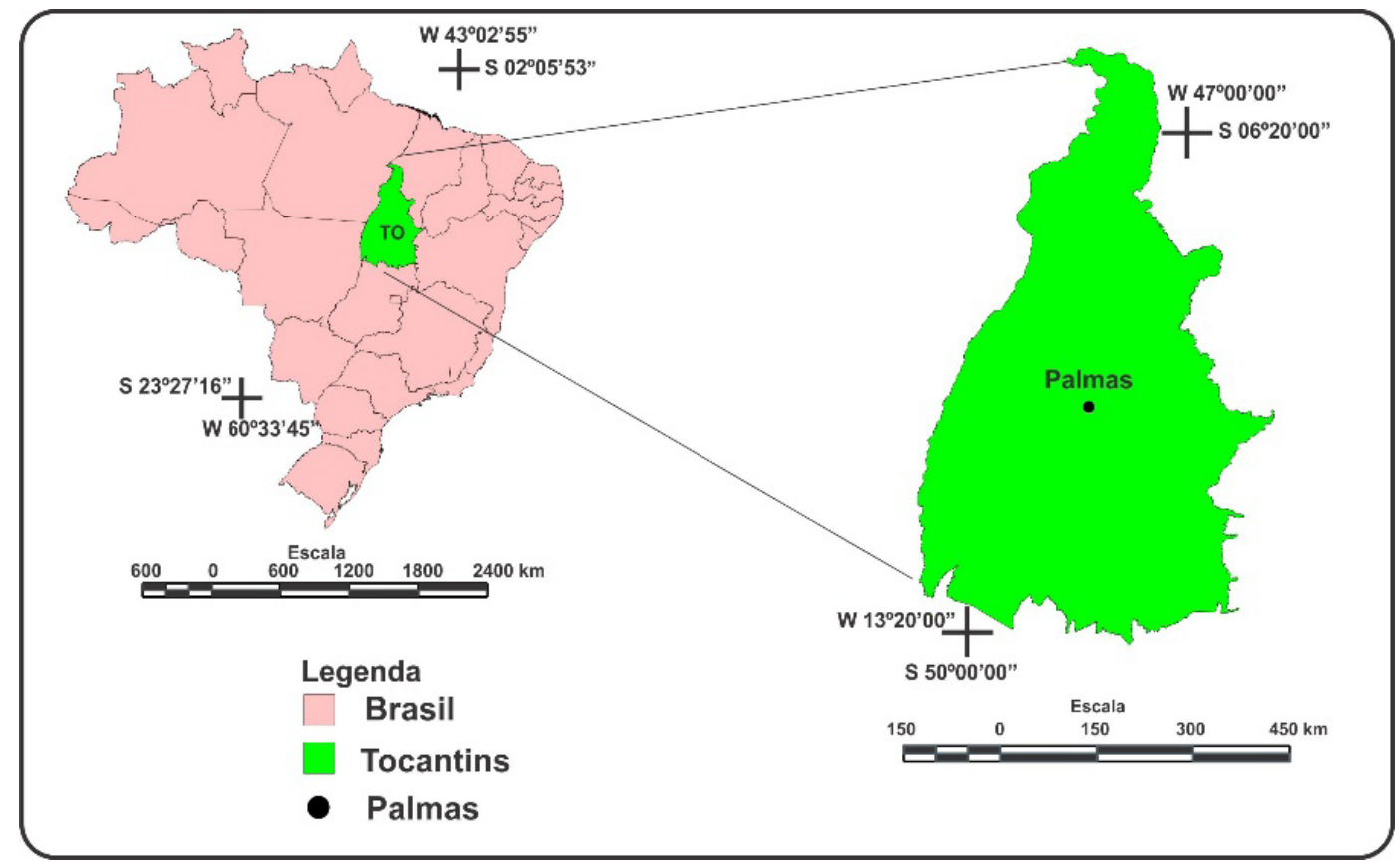

FIGURA 1 - Localização de Palmas.

FONTE: Elaborado pelos autores.

e Sudoeste - quadras chamadas ARSO's (Velasques, 2009). A estratégia de ocupação urbana da cidade foi planejada para ser realizada em etapas bem definidas, conforme a Figura 2, a partir do núcleo central e com sentido Norte-Sul.

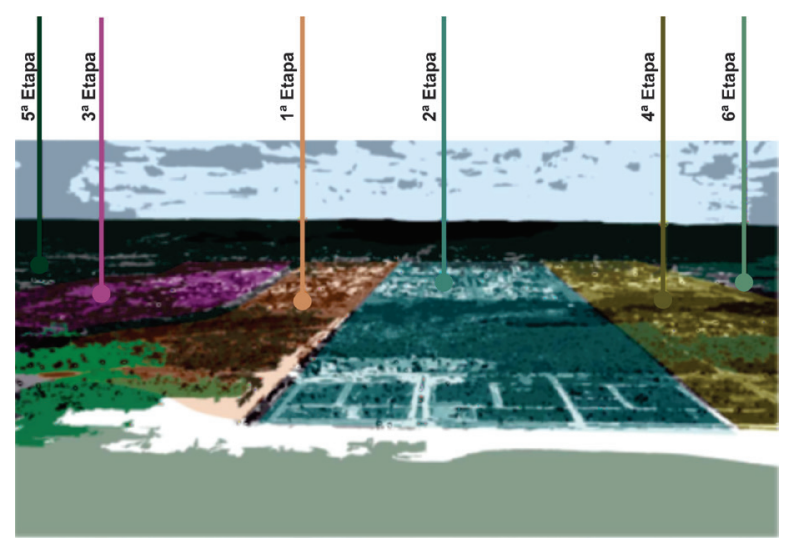

FIGURA 2 - Etapas previstas no plano urbanístico original para ocupação de Palmas.

FONTE: Palmas (2006).
Contudo, nos primeiros anos de ocupação da cidade, um grande contingente de população migrante se instalou em áreas periféricas, antes que as quadras do Plano Diretor Básico fossem ocupadas, contrariando o processo de ocupação a partir do núcleo central (Figura 3). Os mecanismos de formação de preço e de acesso à terra orientaram boa parte da demanda por moradia, sobretudo para os bairros satélites de Taquaralto e para os Jardins Aureny's (I, II, III e IV), bairros formados fora da área do Plano Diretor Básico, e para as quadras ARNO 31, 32 e 33, ocupadas, principalmente, de modo irregular (Kran \& Ferreira, 2006).

Sendo assim, o Governo Estadual, para atender à demanda crescente por habitação, promoveu a regularização das áreas ocupadas irregularmente nas ARNO's e a aprovação de novos loteamentos em Taquaralto e Jardins Aureny's I, II, III e IV.

Diante da situação da cidade, o primeiro plano básico urbano de Palmas foi alterado, tendo sido acompanhado pela incorporação, ao processo de planejamento, dos territórios do município como um todo. Logo, a zona 


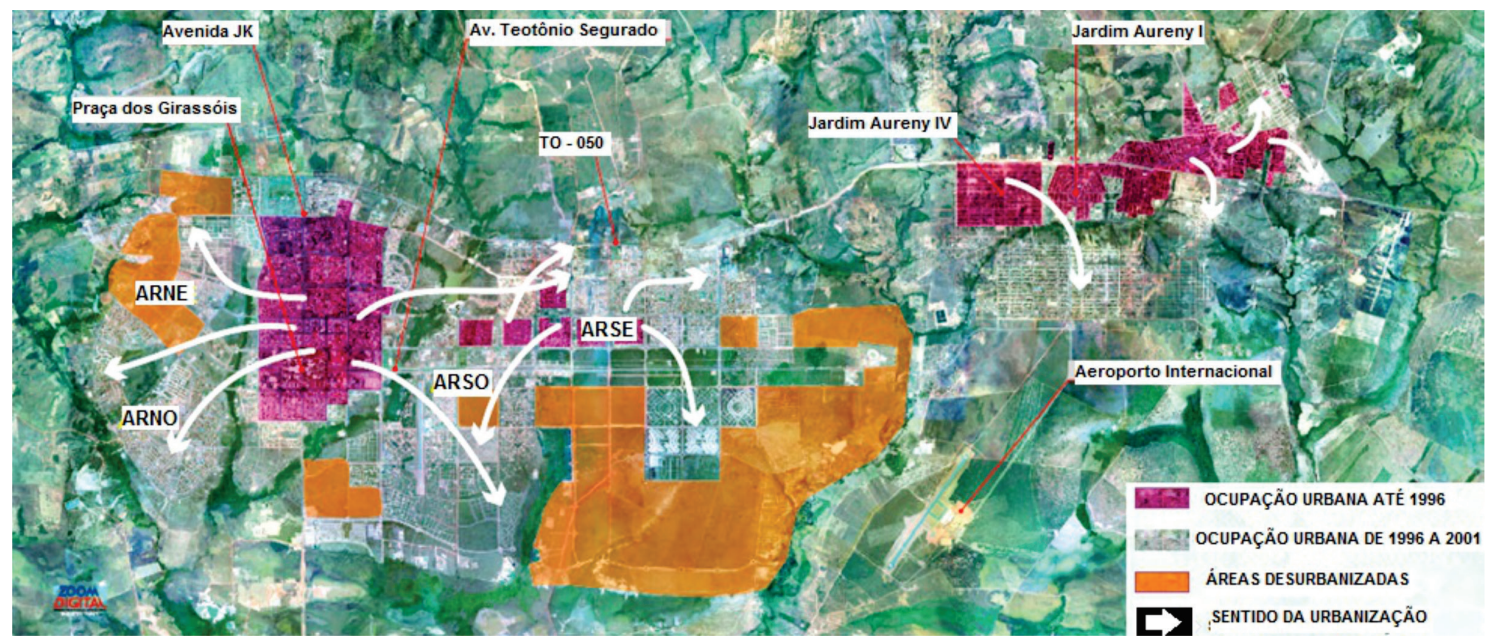

FIGURA 3 - Sentido da ocupação de Palmas.

FONTE: Palmas (2002).

de ocupação urbana teve seu limite estipulado a leste e norte pela área de contorno da Área de Preservação Ambiental (APA) Serra do Lajeado, a oeste pelo lago da Usina Hidrelétrica Luís Eduardo Magalhães e ao sul pelo Ribeirão São João, divisa com o município de Porto Nacional. Também passaram a fazer parte da zona de ocupação urbana os núcleos urbanos dos distritos de Taquaruçu e Buritirana, incorporando todos os loteamentos presentes aprovados (Palmas, 2002).

Apesar de nova e planejada, Palmas "surge como um velho/novo modelo de cidade, velho, no sentido do planejamento administrativo, novo, no sentido de ser uma capital construída pelo 'capital privado', e por ser também a mais nova fronteira do capital urbano no espaço brasileiro" (Lira, 2011, p. 180). Porém, isso não conseguiu evitar problemas comuns a muitas cidades, como os vazios urbanos e todas as suas consequências (Lira \& Carvalhêdo, 2009).

\subsection{A construção do Plano Diretor participativo de Palmas - TO}

Com as novas diretrizes para elaboração de um plano diretor participativo, estabelecidas pelo Estatuto da Cidade, a Secretaria de Desenvolvimento Urbano e
Habitação de Palmas (SEDUH), juntamente com outros órgãos municipais, deu início em 2005 às discussões que culminaram com a elaboração do Plano Diretor Participativo de Palmas, que foi aprovado por lei municipal no ano de 2007.

A elaboração do plano diretor participativo contou com três etapas, seguindo as normas estabelecidas pelo Ministério das Cidades (Brasil, 2005). A primeira etapa teve como objetivo a elaboração da Leitura Técnica, consistindo num relatório formulado por técnicos (não necessariamente da prefeitura, pois podem ser de uma consultoria, por exemplo), apresentando a realidade do município; a etapa seguinte, a elaboração da Leitura Comunitária, trouxe o olhar da comunidade sobre o município, e, por último, elaborou-se o texto final que foi levado para discussão na Câmara Municipal, resultando na Lei Complementar $\mathrm{n}^{\mathrm{O}} 155$.

Para cumprir a primeira etapa, de acordo com Paz (2012), a SEDUH contratou a ONG Associação para a Recuperação e Conservação do Ambiente (ARCA), de Goiânia, para capacitar os funcionários envolvidos e prestar consultoria na realização das audiências. A ONG organizou um curso de pós-graduação lato sensu em Planejamento Urbano e Ambiental, em parceria com a Universidade Federal do Tocantins (UFT). O curso de Pós-Graduação em Planejamento Urbano e Ambiental 
foi dividido em módulos e cada módulo equivalia a um eixo temático a ser discutido no plano diretor, como: uso do solo, desenvolvimento sustentável, habitação, infraestrutura urbana, meio ambiente e mobilidade.

Após a produção do relatório técnico, os alunos do curso de Pós-Graduação, juntamente com uma equipe da Prefeitura de Palmas e com consultoria da ARCA, passaram para a segunda etapa na elaboração do Plano Diretor participativo, a Leitura Comunitária. O primeiro passo, de acordo com Manzano Filho (2012), foi a divisão territorial da cidade, em que se buscavam quadras estratégicas com referência espacial, nas quais fosse possível contar com uma participação ampla da sociedade no âmbito das audiências públicas. No Relatório de Consultas Públicas, são apresentados dados sobre os locais, fotografias das audiências públicas e imagens dos convites que foram distribuídos às comunidades de cada unidade espacial, convidando-as para as audiências.

Aproveitando-se do desenho urbano da cidade de Palmas e dos núcleos urbanos localizados nos demais distritos (Taquaruçu e Buritirana), as audiências públicas foram divididas da seguinte forma (representada na Figura 4): Colégio de Ensino Médio Castro Alves na ARNO 32, com moradores da área norte; Centro de Atenção Integral à Criança no Aureny IV e Feira Coberta do Aureny III, com moradores dos Aureny's; Associação Tocantinense de Municípios, com moradores da área central; Sede dos Pioneiros Mirins de Buritirana, com os moradores do distrito de Buritirana e entorno; Centro Comunitário de Taquaruçu, com os moradores do distrito de Taquaruçu e entorno; Igreja Assembleia de Deus - ARSO 41, com moradores das ARSO's; e Shopping da Cidadania - Taquaralto, com moradores de Taquaralto e entorno.

Além das discussões feitas com a comunidade, Manzano Filho (2012) destaca que a divulgação sobre o plano diretor foi tão efetiva que outros segmentos da sociedade acabaram sendo incorporados. Assim, foram organizados grupos de discussão voltados a atores sociais específicos, como: corretores de imóveis; engenheiros (por meio do
CREA); empresários; moradores da Zona Rural de Palmas e integrantes do setor agropecuário; alunos e professores da Escola Técnica Federal - ETF (atual Instituto Federal de Educação, Ciência e Tecnologia do Tocantins - IFTO) e organizações não governamentais (ONGs).

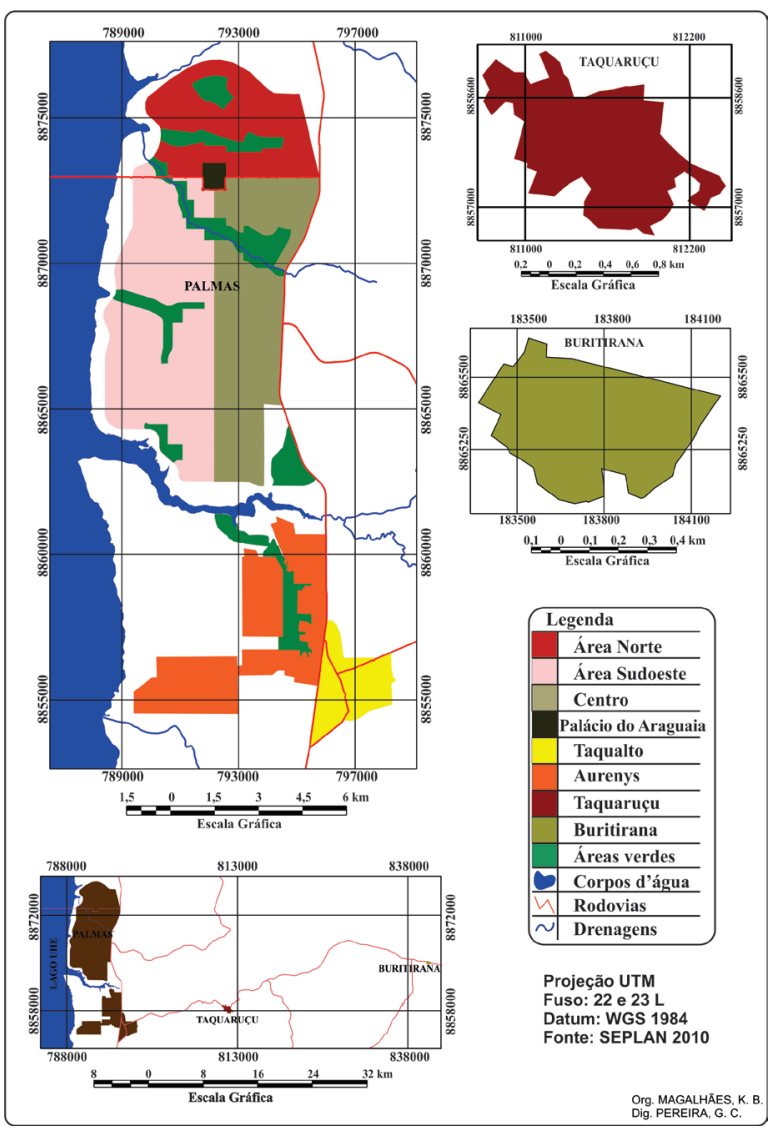

FIGURA 4 - Mapa da cidade de Palmas com a divisão urbana adotada para realização das audiências públicas do Plano Diretor Participativo.

FONTE: Org. Magalhães, K. B.; Dig. Pereira, G. C.

Para instrumentalizar a participação da comunidade, segundo Paz (2012), as audiências seguiam o método ZOPP ${ }^{1}$. Uma preocupação, segundo Manzano

${ }^{1}$ O método ZOPP foi criado pela Cooperação Técnica Alemã - GTZ em 1970. “O princípio básico do método ZOPP é o enfoque participativo, ou seja, a participação ativa no planejamento do projeto de todos aqueles nele diretamente envolvidos” (Egapfundap, 2006, p. 8). E umas das técnicas para participação é o uso de cartolinas retangulares nas quais as pessoas colocam sua contribuição e estas depois são fixadas em um painel de acordo com os eixos temáticos. 
Filho (2012), era evitar que a população ficasse presa unicamente a discussões sobre os problemas dos bairros ou da localidade dos moradores, por isso, antes de cada sessão era realizada uma palestra que explicava o que era o plano diretor e a importância daquela discussão, considerando-se toda a cidade.

Os papéis com os problemas apontados para a cidade eram discutidos e separados de acordo com as temáticas já divididas (uso do solo, desenvolvimento sustentável, habitação, infraestrutura urbana, meio ambiente e mobilidade). Porém, sobre a participação comunitária na elaboração do plano diretor, Silva (2012) destaca a necessidade de cuidados para não se valorizar demais a visão do "leigo" sobre a cidade, em detrimento da visão do "técnico", ou ainda, como ele conclui:

\section{[...] tem hora que você tem que contrariar a população que você está fazendo a liderança ou a gestão, tanto como técnico ou como gestor público, me preocupa um pouco se uma mentira ou um conceito técnico errado for consolidado numa audiência pública (Silva, 2012, p. 3).}

Com relação aos limites da participação popular na realização de audiências públicas, Souza (2010, p. 328-330) destaca os seguintes pontos: o desinteresse de boa parte dos cidadãos nas questões políticas, assim como a falta de interesse por questões coletivas, e ainda, como afirma o autor, "a incapacidade técnica da população comum em participar de decisões sobre assuntos de interesse coletivo". Porém, como continua o autor, um modelo democrático tem seu valor ao permitir que o cidadão se sinta parte do processo, além de permitir o exercício pleno da democracia. É nesse sentido que o papel do técnico assume um caráter de consultoria popular, procurando balizar as discussões que partem do senso comum (Souza, 2010).

Ao final das audiências, foi produzido o Relatório da Leitura Comunitária, que traz de maneira simplificada as discussões de cada reunião realizada. Após isso, a equipe gestora do processo passou para a escrita do texto proposto para aprovação como Plano Diretor de Palmas, levando a cabo a última etapa da elaboração do plano.

\subsection{A representação social do meio ambiente na leitura comunitária do Plano Diretor participativo de Palmas - TO}

Durante as audiências públicas, foram levantados pela população de cada unidade os problemas relacionados ao desenvolvimento sustentável, à gestão, à habitação, à infraestrutura, ao meio ambiente, à mobilidade e ao uso do solo. A leitura desses problemas permite identificar como a população representa cada um desses temas.

Neste sentido, conforme proposto nos objetivos deste trabalho, segue na Tabela 1 a descrição dos problemas ambientais levantados pelos moradores das diversas porções da área urbana de Palmas durante as audiências da Leitura Comunitária do Plano Diretor Participativo, assim como as respectivas representações de meio ambiente. Tais representações foram identificadas a partir das diferentes concepções dos problemas relacionados ao ambiente local, expressas no Relatório da Leitura Comunitária.

A Tabela 1 permite inferir que a maioria dos setores do município de Palmas apresenta uma representação antropocêntrica e sistêmica de meio ambiente, segundo a classificação de Reigota (2004) e Neves (2003), respectivamente. Por se tratar de questões ligadas principalmente à área urbana do município, o ambiente é representado como uma paisagem já modificada ou em processo de modificação pela ocupação urbana. Em geral, é no espaço urbano que se manifestam as mais contundentes intervenções humanas sobre a paisagem natural, concentrando-se aí variados tipos de impactos negativos. Além disso, a concentração da população nas cidades contribui para uma maior percepção dos problemas ambientais que se manifestam junto ao espaço urbano, em detrimento dos problemas ambientais do meio rural.

Na porção norte, por exemplo, a população relatou nas audiências públicas que um dos principais problemas ambientais é constituído pelas avenidas com arborização de baixo porte e pouco sombreamento, bem como o abandono de áreas verdes, cujo principal problema é o montante de lixo depositado nesses locais, que pode lhes causar doenças. Esses problemas demonstram a clara representação de que o meio ambiente está a serviço do homem, ao lhe proporcionar sombra, podendo também ser insalubre para sua sobrevivência. 
TABELA 1 - Problemas ambientais levantados pelos moradores de Palmas durante as audiências da leitura comunitária do Plano Diretor Participativo e a representação de meio ambiente.

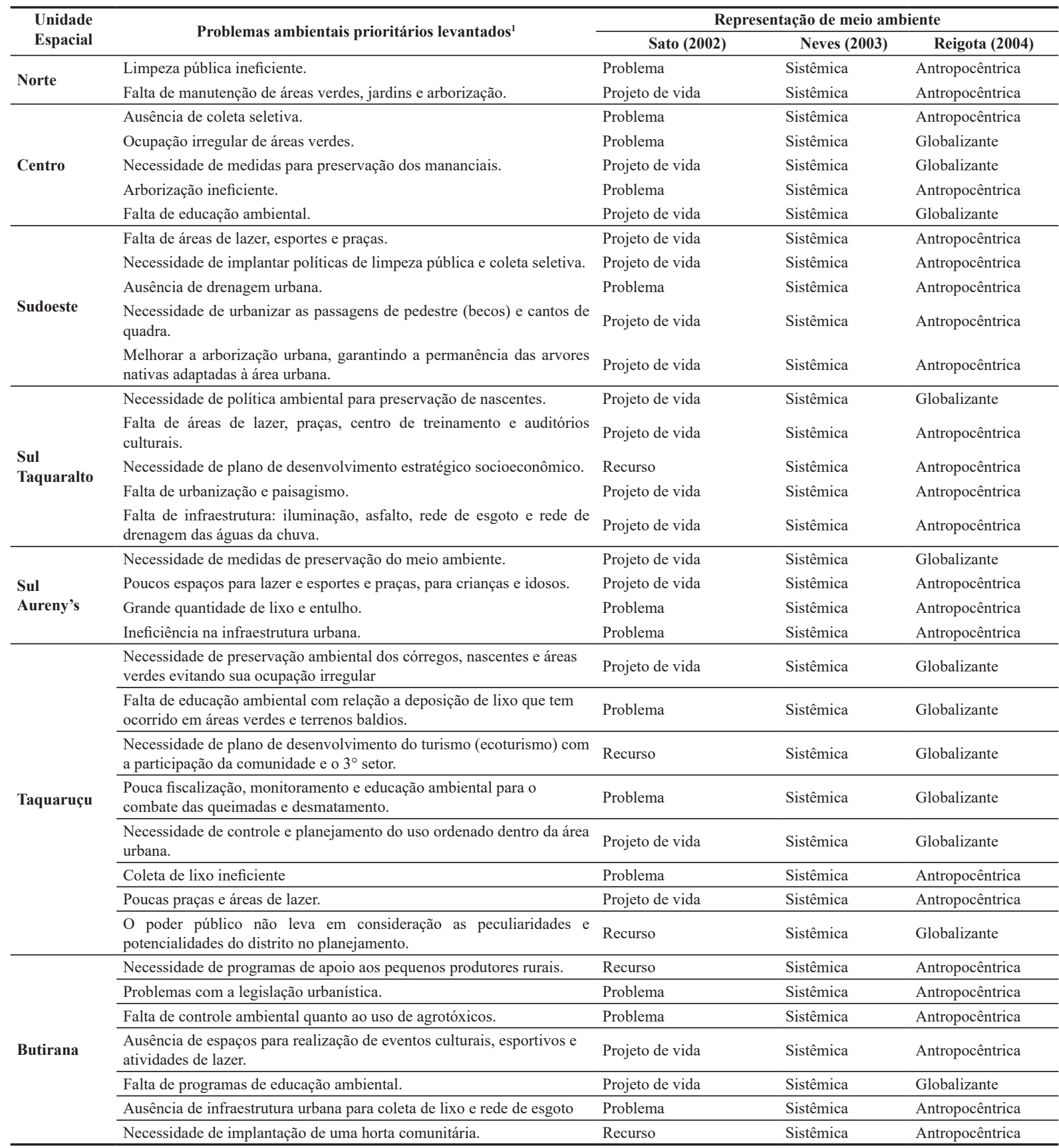

${ }^{1}$ FONTE: Palmas (2006). 
Estes fatores permitem identificar na porção norte do município a representação sistêmica (Neves, 2003) de meio ambiente, na qual qualquer ação humana (conservação/abandono de áreas verdes, disposição adequada/ inadequada de lixo) pode ter uma reação no meio ambiente e vice-versa.

Ressalta-se que as questões apresentadas estão ligadas ao histórico de ocupação da área norte da cidade, pois as quadras dessa área, em contraposição às da área central, apresentam um histórico de ocupação irregular e de pouco investimento do setor público em infraestrutura, moldando sua paisagem e seu contexto urbano (Cocozza et al., 2009).

A parte sul, representada pelos Aureny's, Taquaralto e seu entorno, passou por processo de ocupação semelhante à porção norte. Segundo Costa (2010), são bairros que se constituíram, a princípio, por pessoas de baixa renda que vinham de outras localidades e que não puderam se instalar na área central pela inacessibilidade imposta pelos preços dos terrenos. Assim, a representação de meio ambiente, expressa pelos problemas ambientais, se assemelha em demasia ao caso da porção norte, composta pela falta de infraestrutura, pela ineficiência no sistema de gerenciamento de resíduos e pela necessidade de utilização dos espaços verdes para lazer. Bazolli (2009) aponta que era evidente, devido à distância de dezoito quilômetros da porção central e ao perfil de ocupação, que os moradores da parte sul enfrentariam problemas como transporte urbano, escola, creche, segurança, saneamento e outras necessidades inerentes à qualidade de vida. Essa visão de utilização do meio ambiente pelo homem pode ser comprovada no anseio da população, descrito no relatório de audiência pública, de utilizar uma área verde presente na porção sul como "algo para os idosos terem lazer, usar o local, por exemplo, para pista olímpica" (Palmas, 2006, p. 68).

Contudo, na porção sul, diferente da porção norte, pode ser identificada a representação globalizante de meio ambiente, de acordo com a classificação de Reigota (2004), pois tanto nas audiências realizadas em Taquaralto quanto nas audiências realizadas nos Aureny's, foi levantada a necessidade de medidas/políticas que visem à preservação dos recursos ambientais, concebendo o ser humano como parte integrante do meio e responsável pela sua manutenção.
Bem diferente das porções sul e norte, a área central apresenta a melhor infraestrutura urbana da cidade: pavimentação, praças, transporte público e serviços essenciais, e que hoje desempenha, com o centro comercial no entorno da Praça dos Girassóis, a principal centralidade de Palmas (Cocozza et al., 2009). Contudo, os relatórios das audiências públicas da leitura comunitária do plano diretor demonstram que a população dessa área ora representou o meio ambiente de forma antropocêntrica, ora de forma globalizante, segundo o modelo de Reigota (2004). A concepção do meio ambiente a serviço do ser humano pode ainda ser exemplificada no texto do relatório que oferece sugestão para o problema do reduzido número de árvores: "plantio de árvores de grande porte típicas de nossa região, que produzam sombra e frutos" (Palmas, 2006, p. 40). A concepção globalizante pode ser verificada na necessidade de educação ambiental indicada nos apontamentos sobre a preservação de áreas verdes.

No relatório da leitura comunitária, a população da área central também enfatizou muitos dos problemas ambientais indicados pela população das áreas norte e sul, como a preocupação com a coleta do lixo, a criação de parques em áreas verdes, denotando a representação do meio ambiente enquanto problema e projeto de vida.

Já a porção sudoeste equivale a $46 \%$ do total dos vazios urbanos da cidade. São quadras de baixa densidade populacional e com problemas na infraestrutura urbana, bem retratados no relatório das audiências públicas. Esses vazios resultam da especulação imobiliária e são causadores do elevado custo de urbanização da cidade, pela necessidade de implantação e manutenção da infraestrutura, equipamentos e serviços públicos (Bazolli, 2009). É compreensível que a população dessas quadras anseie por melhorias de suas condições de vida, por meio de intervenções no meio ambiente da área.

Por sua vez, o distrito de Buritirana configura-se como área predominantemente agrícola e com alto grau de carência socioeconômica devido ao baixo nível de renda (Finco \& Silveira, 2008), logo, os principais problemas encontrados refletem a utilização do meio ambiente para a agricultura e para o lazer, conforme demonstrado pela população ao relatar nas audiências públicas que as áreas verdes do distrito estavam sendo ocupadas e que a solução para o problema seria "adaptá-las para prática esportiva e lazer” (Palmas, 2006, p. 87). 
Vale ressaltar que os habitantes desse distrito encontram-se isolados do restante da cidade, devido à sua distância da área central de Palmas, como pôde ser visto na Figura 4, sofrendo com a carência de opções de lazer, localizadas, em sua maioria, no Distrito Sede do Município.

Por último, o Distrito de Taquaruçu foi o local cuja população apresentou a representação globalizante de meio ambiente para a maioria dos problemas ambientais apontados, segundo a classificação de Reigota (2004). Esse distrito possui um conjunto paisagístico diverso, mesclando elementos do Cerrado, da Caatinga e da Floresta Amazônica, compondo seus atrativos turísticos naturais, juntamente com as inúmeras quedas d'água. A comunidade local é direta ou indiretamente envolvida na atividade turística. Segundo trabalho realizado por Milagres et al. (2010), para a comunidade de Taquaruçu a natureza perde gradativamente o significado de fonte de recursos necessários à sobrevivência (água, solo, etc.) para se tornar um recurso cênico e turístico. Este fato coloca o homem numa relação com os demais seres da natureza, sem pressupor seu poder dominante sobre a mesma, e engloba os diversos aspectos: naturais, políticos, sociais, econômicos, filosóficos e culturais.

Foram realizadas, também, audiências com grupos específicos, cuja representação de meio ambiente, conforme os problemas ambientais prioritários por eles levantados, encontra-se listada na Tabela 2. De acordo com problemas relatados por moradores da Zona Rural de Palmas, representantes do setor agropecuário e por alunos e professores da ETF (atual Instituto Federal do Tocantins - IFTO), verifica-se que o meio ambiente, para esses grupos, é representado, em sua maioria, como recurso (fonte econômica a ser utilizada, sem levar em consideração as consequências dos atos espoliativos), e de forma antropocêntrica (onde é tido exclusivamente como meio de exploração de recursos), conforme os modelos Sato (2002) e Reigota, (2004), respectivamente.

Convém ressaltar que entre a população rural a função social da terra foi o único problema representado como projeto de vida, uma vez que é da terra que o homem obtém o local para sua morada e é capaz de extrair alimentos, fruto de seu trabalho, para a manutenção própria e de sua família. Essa representação demonstra a relação de interdependência da sociedade com a natureza e o espaço geográfico, e não apenas como um recurso a ser explorado para fins econômicos.

Os problemas relatados pela equipe técnica da SEDUH, juntamente com organizações não governamentais e ambientalistas, apresentam representação de meio ambiente ora como problema, ora como projeto de vida, pelo modelo de Sato (2002). Pode ser observada ainda a representação sistêmica (que considera vários setores para a resolução de questões ambientais) e globalizante (o homem é visto como um ser integrante do meio), pelos modelos de Neves (2003) e de Reigota (2004).

O conjunto de problemas relatados pelos grupos específicos demonstra especial preocupação com o fenômeno de descuido com os solos e as águas, devido ao município contar com a instalação de atividades agrícolas e pecuárias sem cuidados para a conservação desses elementos.

As obras de engenharia civil também não apresentam a devida preocupação com a proteção dos solos e das águas, restringindo-se frequentemente ao simples lançamento de águas superficiais para fora da área ocupada ou edificada, em especial em obras de estradas e vias públicas, desprovidas de sistemas de drenagem pluvial. Essa prática tem colaborado para o surgimento no município, tanto na zona urbana quanto na rural, de áreas com problemas de erosão, tanto por sulcos erosivos quanto por voçorocas.

Em relação à ocupação irregular das áreas de preservação permanente, o processo de construção e expansão urbana de Palmas tem modificado a evolução dos ecossistemas naturais, alterando a paisagem típica do cerrado. Ocorreram significativas modificações na paisagem de Palmas, evidenciando o acentuado aumento das áreas antropizadas, o desflorestamento expressivo de espécies típicas e uma alteração menos intensa, porém significativa, das matas ciliares, tão importantes na preservação da biodiversidade, na atenuação do aquecimento urbano e com potencialidades estéticas e de lazer (Fighera, 2005). As queimadas, por sua vez, afetam habitualmente áreas verdes de preservação da cidade e áreas públicas municipais (Palmas, 2006).

É relevante, ainda, a preocupação com a falta de saneamento ambiental relacionado ao controle de vetores. Segundo relatório da Secretaria de Planejamento (Seplan, 2004), o aumento de vetores estaria relacionado 
TABELA 2 - Problemas ambientais levantados pelos grupos específicos durante as audiências da leitura comunitária do Plano Diretor Participativo e a representação de meio ambiente.

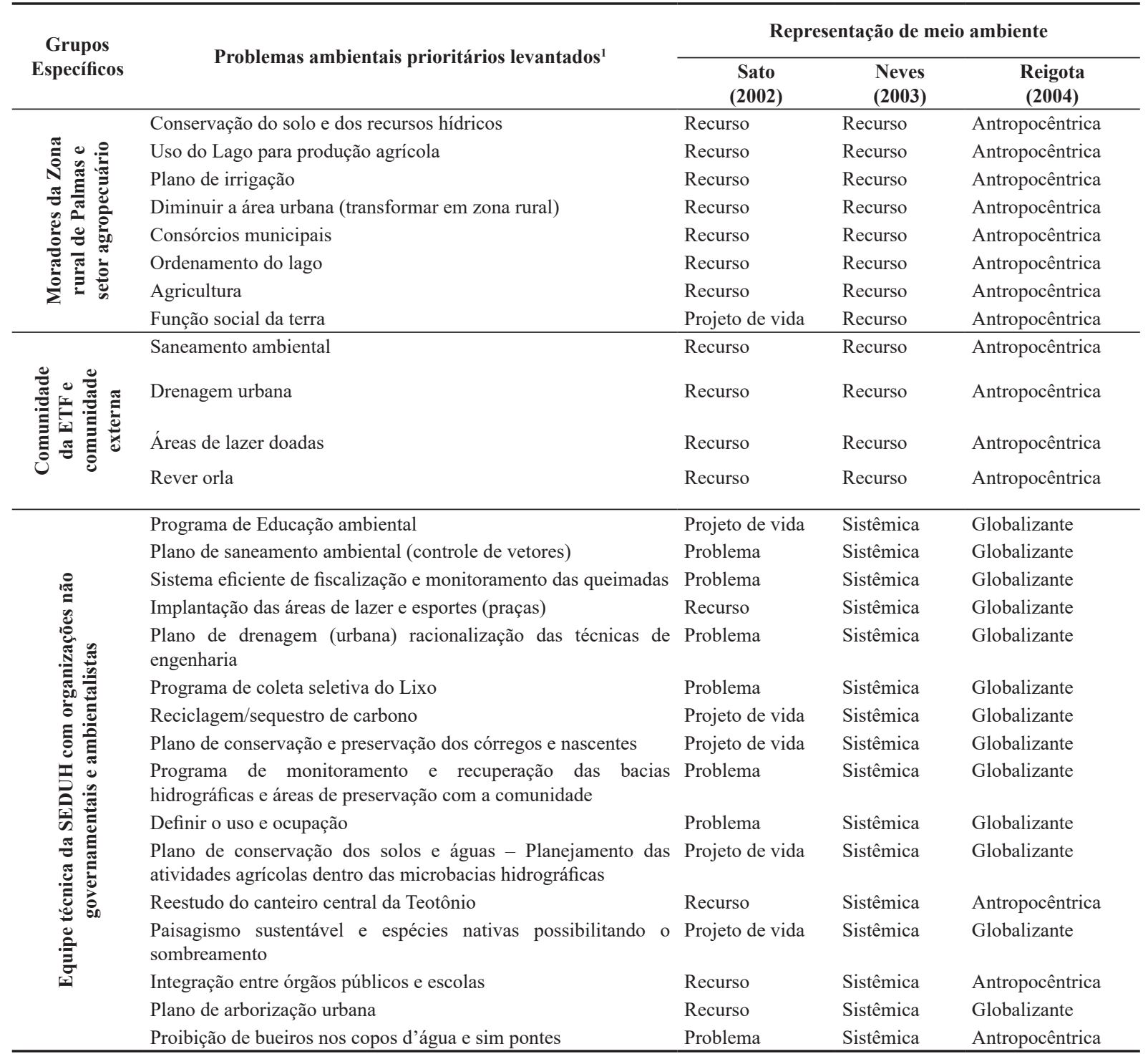

${ }^{1}$ FONTE: Palmas (2006).

aos impactos ambientais causados pela implantação do reservatório da Usina Hidrelétrica Luís Eduardo Magalhães, que teria ocasionado a formação de criadouros potenciais de invertebrados vetores de doenças como, por exemplo, da dengue. Contudo, este pode não ser o único fator para a proliferação desses vetores: o grande número de vazios urbanos ao longo da cidade, onde o lixo se acumula, torna-se um ambiente propício para os vetores de doenças. Logo, a população demonstra que políticas de limpeza pública e de gestão desses espaços 
ociosos devem ser adotadas no texto do plano diretor, com a finalidade de garantir a saúde pública.

\subsection{A representação social de meio ambiente na Lei Complementar $n^{\circ} 155$, de 28 de dezembro de 2007}

O processo para a criação do Plano Diretor Participativo de Palmas, após todas as etapas de discussões entre técnicos, comunidade e legisladores, chega ao seu objetivo final com a criação da lei do plano diretor, que no caso de Palmas é a Lei Complementar n ${ }^{\circ}$ 155/2007. Como esse foi um processo novo, ou seja, com a abertura à participação popular na discussão da cidade e de suas políticas públicas, então, faz-se necessário saber se os anseios da comunidade estão contidos na lei e de que forma foram incluídos no texto.

Nas audiências, dentre os principais assuntos levantados em relação ao meio ambiente pela população (urbana e rural) estão a coleta de lixo, a jardinagem e o paisagismo, os recursos hídricos, as áreas de lazer, o turismo (ligado à geração de renda) e o saneamento. Como já discutido, estes refletem uma visão antropocêntrica (Reigota, 2004) ou como recurso (Sato, 2002) do meio ambiente, em sua maioria.

Como afirma Manzano Filho (2012), a participação popular ocorreu até no momento da escrita do texto do Projeto de Lei Complementar no 14/2006, que, após aprovação na Câmara de Municipal, resultou na Lei Complementar $n^{\circ}$ 155/2007, com 117 artigos. Percebe-se que aquelas mesmas representações de meio ambiente, tanto antropocêntrica (Reigota, 2004) como a de recurso (Sato, 2002), que predominaram na visão da comunidade e dos grupos específicos, estão presentes.

Tal característica fica clara nas expressões usadas em alguns artigos do texto. Por exemplo, no artigo $5^{\circ}$, que trata dos princípios do plano diretor, e mais especificamente no inciso IV, menciona-se a "proteção do meio ambiente e de seus bens comuns e vitais ao homem" (Palmas, 2007, p. 2). Em outras palavras, o meio ambiente que merece proteção é aquele que serve ao homem ou é de seu interesse. Ainda quando algumas questões são levantadas dentro da temática do meio ambiente, talvez na tentativa de atender a estes aclames, surgem algumas expressões cujos significados não estão esclarecidos, tais como "paisagismo sustentável” (art. 13), "arborização sombreadora" (art. 48), "irrigação sustentável” (art. 65) e "IPTU ecológico" e "ISSQN ecológico" (art. 74) ou "ISSQN socioambiental" (Art. 80). Percebe-se que nas discussões não ficou determinado como atender às demandas levantadas, por isso estas expressões parecem refletir mais os desejos da comunidade do que apresentar de modo claro o que se espera ao colocá-las no texto e, posteriormente, em prática na gestão municipal.

A abordagem dessa questão se torna desafiadora, pois, ao analisar as discussões sobre o meio ambiente, percebe-se que os pontos levantados nas audiências são muito específicos e pragmáticos, enquanto que no texto da lei eles aparecem diluídos dentre seus muitos artigos e incisos, em alguns casos de forma vaga. Das propostas apresentadas pelo Projeto de Lei ${ }^{\circ} 14 / 2006$, alguns artigos foram vetados, outros retirados e ainda alguns acrescentados, mas as alterações em relação à proposta inicial foram muito poucas e pontuais. Porém, o que se percebe no texto final é um esforço para atender às demandas levantadas junto à comunidade, pelo menos por meio de diretrizes gerais e com o uso de expressões que tentassem traduzir o anseio popular, ainda que seus aspectos operacionais não estejam suficientemente claros.

\section{Considerações finais}

Os relatórios e as entrevistas que embasaram esta pesquisa ajudaram a construir o percurso que foi realizado na elaboração de algo novo e ao mesmo tempo desafiador: a discussão coletiva da cidade e de suas diretrizes de gestão. Mas, o mais importante, permitiu compreender cada etapa de elaboração do primeiro Plano Diretor Participativo do município de Palmas e fazer uma reconstrução histórica desse processo.

O Plano Diretor Participativo de Palmas passou por muitas etapas, na tentativa de ter como resultado um produto de construção coletiva. O que se percebe é que o conteúdo levantado da leitura comunitária sobre meio ambiente, mesmo sofrendo algumas alterações, encontra-se presente na Lei Complementar $n^{\circ} 155$, aprovada na Câmara Municipal, e que atualmente é a lei que direciona as ações do poder público local. Por conta 
do próprio processo, ou seja, o de transformar todo um conjunto de informações em um texto único, o conteúdo levantado nas audiências públicas acabou sendo diluído e generalizado na lei. Por fim, o documento final criou uma série de expressões e conceitos que dificultam a aplicação prática do que fora antes discutido nas audiências públicas.

Por ser uma experiência nova, faz-se importante entender como as representações da comunidade e dos técnicos em relação à cidade estão constituídas e como foram expressas nos documentos. Ainda, no caso de Palmas, há uma perceptível diferença entre o que está no papel, ou seja, a lei, e de como a cidade se desenvolveu de fato. Isso de certa forma pode desestimular a participação da sociedade na (re)construção do plano diretor, uma vez que a mesma observa que o planejamento muitas vezes deixa de ser obedecido por seus gestores. No entanto, uma experiência ${ }^{2}$ acontecida em tempos recentes pode indicar que a participação popular nas audiências públicas contribuiu para uma tomada de consciência de que a comunidade está inserida no processo de construção da cidade. De modo semelhante, o sucesso do plano participativo está relacionado também ao acompanhamento posterior, pela sociedade.

A teoria da representação social tem importante papel na compreensão do pensamento coletivo, pois ela se refere a como as informações e os conhecimentos são organizados e representados pelos sujeitos. No caso do meio ambiente, as representações são expressas nos discursos e nas atitudes, criando uma imagem ou campo de representações desse objeto. Assim, a partir da teoria das representações sociais, foi possível compreender como os diferentes sujeitos que participaram do Plano Diretor Participativo de Palmas representaram o meio ambiente do município. Do mesmo modo, a utilização das classificações propostas por Sato (2002), Neves (2003) e Reigota (2004) constituiu um suporte que facilitou a compreensão da representação social do meio ambiente e dos problemas ambientais.
Cabe ressaltar que, conforme explicitado pela própria teoria das representações sociais, as vivências, a cultura, a realidade social, os interesses e a ideologia dos diferentes grupos participantes possibilitaram que cada um deles pudesse representar o meio ambiente a sua maneira, contribuindo para que as representações não fossem uniformes. Todavia, é notável que os diversos grupos representem predominantemente o meio ambiente de forma antropocêntrica, o que pode ser explicado pelo pensamento ocidental cristão acerca da natureza, tida como fonte de recursos a serem utilizados pelo homem. Por outro lado, a própria teoria da representação social deve ser utilizada com ressalvas, pois a categorização da representação de meio ambiente, conforme proposta pelos autores Sato (2002), Neves (2003) e Reigota (2004), pode levar a simplificações do conceito e, consequentemente, encobrir novas categorias que representariam o meio ambiente de forma mais realista e detalhada.

A leitura comunitária realizada nas diferentes porções do município de Palmas demonstrou, pela representação de meio ambiente, que os principais problemas ambientais estão ligados à forma de ocupação do território de Palmas, contrária àquela proposta no seu projeto original. Esta leitura evidenciou, ainda, o anseio da população de que o Plano Diretor Participativo viesse resolver os diversos problemas ambientais das diferentes áreas do município.

A revisão do Plano Diretor Participativo de Palmas, que deve ocorrer a partir de 2016, necessita considerar as possíveis falhas ocorridas em sua primeira versão, repensando criticamente o processo de construção. Nesse sentido, o plano diretor deve se reafirmar como instrumento para a gestão e o ordenamento do município, reforçando seu caráter participativo, abarcando os concretos anseios da população e contribuindo para a resolução efetiva de seus problemas ambientais urbanos.

\footnotetext{
${ }^{2}$ No ano de 2011, foi sugerido por um grupo de legisladores municipais um projeto de lei que propunha a ampliação do perímetro urbano de Palmas. Porém, como mostra estudo feito por Bazolli (2012, p. 287), a população se mostrou contrária a esta medida, pois a participação popular deu-se "neste período de embate, com presença nas manifestações, nas redes sociais, nas rádios e nos demais meios de comunicação, demonstrando que a população está[va] consciente e refuta[va] a atitude dos vereadores".
} 


\section{Referências}

Antunes, P. B. Direito Ambiental. 9. ed. Rio de Janeiro: Lumen Juris, 2006.

Bazolli, J. A. Os efeitos dos vazios urbanos no custo de urbanização da cidade de Palmas - TO. Estudos Geográficos, 7(1), 103-123, 2009.

Bazolli, J. A. Dispersão urbana e instrumentos de gestão: dilemas do poder local e da sociedade em Palmas/TO. 2012. 336f. Uberlândia, Tese (Doutorado em Geografia) - Universidade Federal de Uberlândia, MG, 2012.

Brasil. Lei $n^{\circ} 10.257$, de 10 de julho de 2001. Regulamenta os arts. 182 e 183 da Constituição Federal, estabelece diretrizes gerais da política urbana e dá outras providências. Brasília, 2001.

Brasil. Ministério das Cidades. Plano diretor Participativo: guia para elaboração pelos municípios e cidadãos. 2. ed. Brasília: Confea, 2005.

Cocozza, G. P.; Oliveira, L. A.; Santiago, A. A.; Sousa, D. A.; Coelho, J. S. Palmas: por um sistema de espaços livres. Paisagem Ambiente: Ensaios, 26, 73-87, 2009.

Costa, A. S. V. O espaço urbano e a segregação em Palmas-TO: um estudo de caso sobre o bairro Jardim Aureny I. In: Anais Eletrônicos da $16^{a}$ Semana de Planejamento Urbano e Regional, 2010, Rio de Janeiro. Rio de Janeiro: UFRJ, 2010. Disponível em: <http://www.ippur.ufrj.br/download/ semana_pur_2010/completos/adenilsonpalmas.pdf $>$. Acesso em: 08 jan. 2013.

Dornelas, H. L.; Pessanha, R. R.; Ribeiro Filho, G. B. Gestão urbana e tributária frente ao Estatuto da Cidade e à Lei de Responsabilidade Fiscal: o caso do município de Muriaé (MG). R. Ciênc. Humanas, 1(2), 163-170, 2001.

Durkheim, É. Representações individuais e representações coletivas. Sociologia e Filosofia. Rio de Janeiro: Forense Universitária, 1970.

Fighera, D. da R. A efetividade do projeto de cidade ecológica de palmas pelos seus espaços verdes. 2005.187f. Palmas, Dissertação (Mestrado em Ciências do Ambiente) - Universidade Federal do Tocantins, 2005.

Finco, M. V. A.; Silveira, P. V. Buscando o Desenvolvimento Sustentável: um estudo sobre a relação entre pobreza e meio ambiente na Região do Cinturão Verde, Palmas/Tocantins. Gaia Scientia, 1(2), 61-72, 2008.
Jodelet, D. Représentations sociales: un domaine en expansion. In: Jodelet, D. (Ed.). Les représentations sociales. Tradução: Tarso Bonilha Mazzotti. Revisão Técnica: Alda Judith Alves Mazzotti. UFRJ - Faculdade de Educação, dez. 1993. Paris: PUF, 1989. p. 31-61.

Kran, F.; Ferreira, F. P. M. Qualidade de vida na cidade de Palmas - TO: uma análise através de indicadores habitacionais e ambientais urbanos. Ambiente \& Sociedade, 9(2), 2006.

Lira, E. R. A gênese de Palmas - Tocantins: a geopolítica de (re) ocupação territorial na Amazônia Legal. Goiânia: Kelps, 2011.

Lira, E. R.; Carvalhêdo, W. S. Palmas ontem e hoje: do interior do cerrado ao portal da Amazônia. Observatorium: Revista Eletrônica de Geografia, 1(2), 51-73, 2009.

Manzano Filho, E. 21 nov. 2012. 1 fita cassete (18 min.). Entrevista concedida aos autores.

Milagres, V. R., Souza, E. M.; Souza, L. B. Percepção ambiental no Distrito de Taquaruçu, Município de Palmas (TO): a relação dos moradores com as transformações da paisagem ao longo da história local. Caderno Virtual de Turismo, 1(10), 1-14, 2010.

Moscovici, S. A representação social da psicanálise. Rio de Janeiro: Zahar, 1978.

Moscovici, S. Representações sociais: investigações em psicologia social. Petrópolis, RJ: Vozes, 2003.404 p.

Neves, D. A. F. As concepções sobre meio ambiente, educação e educação ambiental em dissertações de três universidades paulistas. In: Anais Eletrônicos do $4^{\circ}$ Encontro Nacional de Pesquisa em Educação em Ciências, 2003, Bauru, SP. Bauru: Universidade de São Paulo, 2003. Disponível em: $<$ http://fep. if.usp.br/ profis/arquivos/ivenpec/Arquivos/Orais/ORAL040. pdf $>$. Acesso em: 20 out. 2012.

Oliveira, A. C. R.; Sahr, C. L. L. Induções nas transformações do uso e ocupação do solo urbano em Ponta Grossa-PR.Terr@ Plural, 6(1), 109-123, 2012.

Palmas. Prefeitura de Palmas. Caderno de Revisão do Plano Diretor de Palmas: Plano Diretor de Ordenamento Territorial. Palmas/TO, 2002.

Palmas. Prefeitura de Palmas. Relatório. Consultas Públicas. Plano Diretor Participativo de Desenvolvimento Territorial do Município de Palmas. Secretaria Municipal de Desenvolvimento Urbano e Habitação. Palmas/TO, 2006. 
Palmas. Prefeitura de Palmas. Lei Complementar $n^{\circ} 155$, de 28 de dezembro de 2007. Dispõe sobre a política urbana do município de Palmas. Palmas/TO, 2007.

Paz, L. H. 28 nov. 2012. 1 fita cassete (24min.). Entrevista concedida aos autores.

Queiroz, A. C. P.; Braga Junior, J. L.; Marques, L. P.; Paz, L. H. F.; Quintanilha, M.; Brito, P. G.; Pinho, R.; Sobreira, V. L. R. Diagnóstico de Sustentabilidade. 2006. 134 f. Palmas, Trabalho de conclusão de curso (Especialização em Planejamento Urbano e Ambiental) - Universidade Federal do Tocantins, 2006.

Reigota, M. Meio ambiente e representação social. São Paulo: Cortez, 2004.

Ribeiro, L. C. de Q.; Cardoso, A. L. Reforma urbana e gestão democrática: promessas e desafios do Estatuto da Cidade. Rio de Janeiro: Revan/FASE, 2003.

Saleme, E. R.; Silva, S. T. Plano Diretor, participação popular e responsabilidades. In: Anais Eletrônicos do $15^{\circ}$ Congresso Nacional do Conpedi, 2006, Manaus. Florianópolis: Fundação Boiteux, 2006. Disponível em: <http://www.conpedi.org.br/ manaus/arquivos/anais/bh/edson_ricardo_saleme.pdf $>$. Acesso em: 20 out. 2012.

Sato, M. Educação Ambiental. São Carlos: Rima, 2002.
Sauvé, L. Uma cartografia das correntes em educação ambiental. In: Sato, M.; Carvalho, I. Educação ambiental: pesquisa e desafios. Porto Alegre: Artmed, 2005.

SEPLAN - Secretaria Estadual do Planejamento e Meio Ambiente. Plano das bacias hidrográficas do entorno de Palmas - TO. 2004.

Silva, R. T. de L. e. Brasil, 11 dez. 2012. 1 fita cassete (1h17min.). Entrevista concedida aos autores.

Sousa, A. L. Território da Habitação no processo do Plano Diretor Participativo da cidade de Fortaleza/CE, Brasil. Scripta Nova: Revista Electrónica de Geografía y Ciencias Sociales, 14(331), 2010. Disponível em: <http://revistes.ub.edu/index. php/ScriptaNova/article/view/1660>.

Souza, M. L. Mudar a cidade: uma introdução crítica ao planejamento e à gestão urbanos. 6. ed. Rio de Janeiro: Bertrand Brasil, 2010.

Stephan, I. I. C.; Rocha, R. F. Planos diretores: que participação é essa? Revista Tecnológica, Edição Especial ENTECA 2009, 107-116, 2009.

Velasques, A. B. A. Palmas (1989): a última capital planejada do século XX. In: Anais do $8^{\circ}$ Seminário Docomomo Brasil, 2009, Rio de Janeiro. Rio de Janeiro, 2009.

Vergara, S. C. Métodos de pesquisa em administração. São Paulo: Atlas, 2006. 